\title{
AS POLÍTICAS DE EDUCAÇÃO E CUIDADOS NA PRIMEIRA INFÂNCIA PARA A AMÉRICA LATINA: INTENCIONALIDADES E ENCAMINHAMENTOS NA PROPOSTA DA UNESCO
}

\author{
LAS POLÍTICAS DE EDUCACIÓN Y CUIDADOS EN LA PRIMERA INFANCIA PARA \\ AMÉRICA LATINA: INTENCIONALIDADES Y ENCAMINAMIENTOS EN LA \\ PROPUESTA DE LA UNESCO
}

\author{
THE POLICIES OF EARLY CHILDHOOD EDUCATION AND CARE FOR LATIN \\ AMERICA: INTENTIONALITIES AND REFERRALS IN THE UNESCO PROPOSAL
}

\author{
Camila Maria BORTOT ${ }^{1}$ \\ Ângela Mara de Barros LARA ${ }^{2}$
}

RESUMO: O objetivo do presente texto é analisar as orientações e tendências da Organização das Nações Unidas para a Educação, a Ciência e a Cultura, voltadas para a Educação e Cuidados na Primeira Infância (ECPI) aos países da América Latina. A metodologia adotada foi a pesquisa documental, por meio de levantamento deste Organismo Internacional, analisados à luz da literatura atinente. Conclui-se que as intencionalidades e tendências direcionam-se: à educação escolar dos anos finais da Educação Infantil como preparatória ao ensino fundamental; e ao cuidado por vias não formais para a educação de zero a três anos, com medidas focalizadas, intergerenciais e intersetoriais, voltadas para a gestão da pobreza, distante da perspectiva do direito à educação de qualidade, principalmente, quando as parcerias com o privado são amplamente destacadas.

PALAVRAS-CHAVE: Políticas para a Educação Infantil. América Latina. ECPI. UNESCO.

RESUMEN: El objetivo del presente texto es analizar las orientaciones y tendencias de la Organización de las Naciones Unidas para la Educación, la Ciencia y la Cultura, orientadas a la Educación y Cuidados en la Primera Infancia (ECPI) a los países de América Latina. La metodología adoptada fue la investigación documental, a través del levantamiento de este organismo internacional, analizados de acuerdo con la literatura pertinente. Se concluye que las intencionalidades y tendencias se dirigen: a la educación escolar de los años finales de la Educación Infantil como preparatoria a la enseñanza fundamental; y, al cuidado por vías no formales para la educación de cero a tres años, con medidas focalizadas, intergenciales e intersectoriales, orientadas a la gestión de la pobreza, distante de la perspectiva del derecho a la educación de calidad, principalmente, cuando las alianzas con el privado son ampliamente destacadas.

\footnotetext{
${ }^{1}$ Universidade Federal do Paraná, Curitiba - Paraná - Brasil. Doutoranda em Educação pela UFPR. Mestre em Educação pela UEM. Bolsista da Coordenação de Aperfeiçoamento de Pessoal de Nível Superior. ORCID: https://orcid.org/0000-0002-9355-8876. E-mail: camilabortot@hotmail.com

${ }^{2}$ Universidade Estadual de Maringá, Maringá - PR - Brasil. Professora Associada Aposentada da UEM. Doutora em Educação pela Universidade Estadual Paulista Júlio Mesquita Filho e Pós-Doutorado pela Universidade Federal de Santa Catarina. ORCID: http://orcid.org/0000-0001-8799-8413. E-mail: angelalara@ymail.com
} 
PALABRAS CLAVE: Políticas para la Educación Infantil. América Latina. ECPI. UNESCO.

ABSTRACT: The purpose of the text is to analyze the orientations and trends of the United Nations Education, Scientific and Cultural Organization, focusing on Early Childhood Care and Education (ECCE) to Latin American countries. The methodology adopted was documentary research, through a survey of this international organization, analyzed according to the relevant literature. It is concluded that the intentionalities and tendencies are directed to: school education in the final years of Early Childhood Education as a preparatory to elementary school; and, care for non-formal education for zero to three years, with focused, intergenerational and intersectoral measures, directed to management of poverty, away from the perspective of the right to quality education, especially when partnerships with the private sector are widely highlighted.

KEYWORDS: Policies for Early Childhood Education. Latin America. ECCE. UNESCO.

\section{Introdução}

É manifesta a centralidade das discussões que versam sobre as crianças e seus direitos, sendo esse inclusive o tema de diferentes conferências e reuniões internacionais e regionais. Dentre os direitos aí referidos, o direito à educação infantil configurou-se como uma questão fundamental para os governos locais (CAMPOS, 2013). Dentro do direito à Educação Infantil, observamos mediações dos Organismos Internacionais (OI) sobre Educação e Cuidados na Primeira Infância (ECPI) aos países latino americanos.

Objetivamos analisar as orientações e tendências da Organização das Nações Unidas para a Ciência e Cultura (UNESCO) voltadas para a ECPI aos países da América Latina, buscando responder: Para que ações à ECPI ganharam notoriedade e orientaram políticas para a Educação Infantil em países latino-americanos?

A partir do referencial analítico de políticas conceituado por Dale (2001; 2004) como Agenda Globalmente Estruturada para Educação (AGEE), a metodologia adotada foi de caráter documental, o que exigiu apreciação e valoração, considerando que os documentos são, frequentemente, contraditórios, e por isso devem ser lidos em relação ao tempo e contexto particulares em que foram produzidos, além de também serem confrontados com outros do mesmo período e local (SHIROMA; CAMPOS; GARCIA, 2005).

A pesquisa foi desenvolvida por meio de um estudo bibliográfico e documental, que para além de teóricos que debatem a temática, selecionamos por principais fontes: "Bases sólidas: educação e cuidados na primeira infância - Relatório Conciso (2007)" e "Declaração 
de Incheon Educação 2030: rumo a uma educação de qualidade inclusiva e equitativa e à educação ao longo da vida para todos" $(2015 a)^{3}$, ambos da UNESCO.

A empiria foi estruturada em dois momentos: primeiramente contextualizamos quando as orientações para a educação infantil pelos OI ganham destaque e quando países da América Latina se tornam signatários; em seguida, analisamos as intencionalidades e encaminhamentos sobre ECPI em relatórios da UNESCO supracitados.

\section{ECPI e a criação de agenda estruturada aos países latino-americanos}

A criação de uma agenda para a Educação Infantil na América Latina, mediada pelos Organismos Internacionais, não é nova. Alguns marcos do início do século XX podem ser mencionados: Declaração de Genebra sobre os Direitos da Criança, de 1924; Declaração sobre os Direitos da Criança, adotada pela Assembleia Geral das Nações Unidas, em 20 de novembro de 1959; Pacto Internacional de Direitos Econômicos, Sociais e Culturais, também de 1966 (art. $10)$.

Em 1989 foi realizada a Convenção sobre os Direitos da Criança, organizada pela ONU. Ressalta o preâmbulo da Convenção, a importância da cooperação internacional para a melhoria das condições de vida das crianças em todos os países, em particular nos países em desenvolvimento, onde se concentra um grande número de crianças social e economicamente marginalizadas (ONU, 2002; ROSERMBERG; MARIANO, 2010).

A América Latina e o Caribe foram os primeiros a ratificar o documento da Convenção, visto que, segundo Méndez (2001), a sua aprovação e difusão na região coincidiu com o retorno à democracia em vários países, o que sugere que a linguagem progressista dos novos direitos da criança se ajustava e impulsionava a reconstrução da democracia na região, bem como adentrar na agenda política internacional. Isso implica uma mudança na relação entre o Estado e a infância, colocando esta última no centro da agenda como sujeito de direitos (LÓPEZ; D’ALESSANDRE, 2015). Chile e Panamá assinaram a Convenção, porém, somente existem projetos apresentados no parlamento.

${ }^{3}$ A escolha desses documentos se deu de forma intencional, pois objetivamos traçar uma linha contínua acerca de questões espaciais e temporais, já que, no século XXI, identificamos vários outros estudos e relatórios que vão ao encontro dos selecionados. 
Quadro 1 - Países da América Latina e Caribe na assinatura e ratificação da Convenção sobre os Direitos da Criança

\begin{tabular}{|l|l|l|l|}
\hline \multicolumn{1}{|c|}{ País } & \multicolumn{1}{c|}{ Assinatura } & \multicolumn{1}{c|}{ Ratificação } & Entrada em vigor no país \\
\hline Argentina & $26 / 6 / 1990$ & $4 / 12 / 1990$ & $3 / 1 / 1991$ \\
\hline Bolívia & $8 / 3 / 1990$ & $26 / 6 / 1990$ & $2 / 9 / 1990$ \\
\hline Brasil & $26 / 1 / 1990$ & $24 / 9 / 1990$ & $24 / 10 / 1990$ \\
\hline Colômbia & $26 / 1 / 1990$ & $28 / 1 / 1991$ & $24 / 10 / 1991$ \\
\hline Costa Rica & $26 / 1 / 1990$ & $21 / 8 / 1990$ & $20 / 9 / 1990$ \\
\hline Cuba & $26 / 1 / 1990$ & $21 / 8 / 1991$ & $20 / 9 / 1991$ \\
\hline Rep. Dominicana & $8 / 8 / 1990$ & $11 / 6 / 1991$ & $11 / 7 / 1991$ \\
\hline Equador & $26 / 1 / 1990$ & $23 / 3 / 1990$ & $2 / 9 / 1990$ \\
\hline El Salvador & $26 / 1 / 1990$ & $10 / 7 / 1990$ & $2 / 9 / 1990$ \\
\hline Guatemala & $26 / 1 / 1990$ & $6 / 6 / 1990$ & $2 / 9 / 1990$ \\
\hline Honduras & $31 / 5 / 1990$ & $10 / 8 / 1990$ & $9 / 9 / 1990$ \\
\hline México & $26 / 1 / 1990$ & $21 / 9 / 1990$ & $21 / 10 / 1990$ \\
\hline Nicarágua & $6 / 2 / 1990$ & $5 / 10 / 1990$ & $4 / 11 / 1990$ \\
\hline Paraguai & $4 / 4 / 1990$ & $25 / 9 / 1990$ & $25 / 10 / 1990$ \\
\hline Peru & $26 / 1 / 1990$ & $4 / 9 / 1990$ & $4 / 10 / 1990$ \\
\hline Uruguai & $26 / 1 / 1990$ & $20 / 11 / 1990$ & $20 / 12 / 1990$ \\
\hline Venezuela & $26 / 1 / 1990$ & $13 / 9 / 1990$ & $13 / 10 / 1990$ \\
\hline
\end{tabular}

Fonte: organizado pelas autoras a partir dos dados do Sistema de Información sobre la Primera Infancia en América Latina, 2019.

Apesar das ações para assegurar os Direitos às crianças nos países e a cooperação internacional firmada na Convenção, o acirramento das contradições sociais, com o crescimento das desigualdades sociais, expressas pelos elevados índices de crescimento da pobreza e do desemprego na região latino-americana, fez com que, nos anos de 1990, governos e OI, tais como Banco Mundial, Comissão Econômica para a América Latina e o Caribe (CEPAL), UNESCO e Fundo Internacional de Emergência para a Infância das Nações Unidas (UNICEF), apresentassem proposições em favor de um ajuste com rosto humanizado, o que podem ser traduzidas em políticas focalizadas e assistencialistas (CARCANHOLO, 2010; ROSEMBERG, 2015).

Com as ações, percebemos que a pobreza diminuiu significativamente, em grande medida pela benevolência de programas de transferência de renda, porém, ao mesmo tempo, os percentuais e os contingentes de pobres ainda são altos. Entre 2014 e 2017, o aumento da taxa de pobreza e o crescimento da população reforçaram-se mutuamente, o que se traduziu num aumento do número absoluto de pessoas pobres, acima do aumento da taxa de pobreza, com projeção para 2018 de 182 milhões de pessoas na pobreza e 63 na extrema pobreza (CEPAL, 2019).

"Um mundo apropriado para as crianças!" foi o lema que reuniu agências ligadas à ONU, representantes de organizações sociais e chefes de Estado na última década do século XX, na Cúpula Mundial pelos Direitos da Infância, em 1990, patrocinada pela ONU. O objetivo 
era a construção de uma agenda política destinada a responder às questões que tornam a infância contemporânea uma nova questão social. A “agenda", articulada especialmente por organismos internacionais, tais como UNESCO, UNICEF, Banco Mundial e outros que atuam mundialmente, tem forte poder mobilizador nas diferentes regiões do mundo, seja pela atuação direta destes organismos no financiamento de programas de baixo custo, seja por sua inserção indireta, atuando como indutores de políticas locais, via acordos e pactos partilhados com os governos nacionais (CAMPOS, 2008; 2013).

A infância adentra a pauta de forma mais incisiva a partir do início dos anos 2000, de forma a entender o planejamento de ações transnacionais que envolvam a ECPI, com notoriedade a partir Convenção dos Direitos das Crianças (1989) e a Cúpula Mundial em Favor da Infância (1990), que são marcos para os programas destinados à educação infantil, inclusive para aqueles centrados na veiculação de estratégias para o alívio da pobreza.

Se pensarmos em definição ao tema, podemos entender a perspectiva da ECPI pelo documento "Educação e Cuidado na Primeira Infância: grandes desafios", de 2002, que contém a expressão: “[...] inclui todas as modalidades que garantem a educação e cuidado das crianças com idade inferior à da escolaridade obrigatória, seja qual for a estrutura, o financiamento, os horários de funcionamento ou o conteúdo dos programas" (UNESCO; OCDE, 2002, p. 13)4.

O desencadeamento de várias reuniões e desenvolvimento de diversas ações e programas foram baseadas nas evidências das condições impróprias de vida de grande parte das crianças na atualidade. Produziu-se 'relativos consensos', sobretudo, por OI via projetos, financiamentos e intervenção na ação dos governos nacionais e/ou de organizações nãogovernamentais, que se concentram, especialmente, na definição de metas para a infância, ações emergenciais e paliativas.

Analiticamente, aferimos que os OI são vistos como agentes que desempenham um papel fundamental de levar a mensagem da Cultura Educacional Mundial Comum (CMEC) e a organização de uma AGEE (DALE, 2004). Os princípios, as normas, as regras e os procedimentos da cultura da política mundial global, em que os Estados-nação atribuem certa eficiência causal às organizações, no que diz respeito à convergência de práticas nacionais. Consequentemente, têm um papel de veiculação da CEMC. Já AGEE se traduz no como os Estados interpretam e respondem à agenda comum que a CEMC estabelece (DALE, 2001). A AGEE, assim, procura mostrar como uma força supranacional afeta as políticas e práticas

4 Cabe salientar que Organização para a Cooperação e Desenvolvimento Econômico (OCDE) não atua, diretamente, para a América Latina. Dessa forma, utilizamos apenas do conceito de ECPI ali tratado, mas não apresentamos análises sobre suas orientações por não ter como foco a regionalidade aqui tratada. 
educativas nacionais. Para a Educação Infantil, podemos entender a organização de uma AGEE de ECPI, conforme o quadro 2, que aponta a UNESCO como protagonista.

Quadro 2 - Documentos Internacionais

\begin{tabular}{|c|c|c|}
\hline Ano & Autor & Documento \\
\hline 1959 & ONU & Declaração Universal dos Direitos das Crianças \\
\hline 1989 & ONU & Convenção sobre os Direitos das Crianças \\
\hline 1990 & UNESCO & $\begin{array}{l}\text { Declaração Mundial sobre Educação para Todos: satisfação das } \\
\text { necessidades básicas de aprendizagem }\end{array}$ \\
\hline 2000 & UNESCO & The Dakar Framework for Action \\
\hline 2002 & $\begin{array}{l}\text { UNESCO; } \\
\text { OCDE }\end{array}$ & Educação e Cuidado na Primeira Infância: grandes desafios \\
\hline 2002 & ONU & $\begin{array}{l}\text { Um mundo para as crianças: Relatório do Comitê Ad Hoc Pleno da } \\
\text { vigésima sétima sessão especial da Assembleia Geral (ONU) }\end{array}$ \\
\hline $2004 \mathrm{a}$ & $\begin{array}{l}\text { UNESCO; } \\
\text { OREALC }\end{array}$ & Participación de las familias en la Educación Infantil Latinoamericana \\
\hline $2004 b$ & UNESCO & Síntesis regional de indicadores de la primera infancia \\
\hline 2007 & UNESCO & $\begin{array}{l}\text { Bases sólidas: educação e cuidados na primeira infância - Relatório } \\
\text { Conciso }\end{array}$ \\
\hline 2010 & UNESCO & $\begin{array}{l}\text { Conferência Mundial sobre Educação e Cuidado na Primeira Infância: } \\
\text { Marco de Ação e de Cooperação de Moscou; aproveitar a riqueza das } \\
\text { Nações }\end{array}$ \\
\hline 2013 & UNESCO & $\begin{array}{l}\text { Projeto de aceleração do quadro EPT para o "salto decisivo": iniciativa para } \\
\text { a EPT: 2013-2015 }\end{array}$ \\
\hline 2014 & UNESCO & $\begin{array}{l}\text { BRICS Construir a educação para o futuro Prioridades para o } \\
\text { desenvolvimento nacional e a cooperação internacional }\end{array}$ \\
\hline 2014 & UNESCO & Ensinar e Aprender: alcançar a qualidade para todos - Relatório Conciso \\
\hline 2014 & UNESCO & 2014-2021 Medium-Term Strategy \\
\hline $2015 \mathrm{a}$ & UNESCO & $\begin{array}{l}\text { Declaração de Incheon - Educação 2030: rumo a uma educação de } \\
\text { qualidade, inclusiva e equitativa e à educação ao longo da vida para todos }\end{array}$ \\
\hline $2015 b$ & UNESCO & Educação para todos 2000-2015: progressos e desafios - Relatório Conciso \\
\hline
\end{tabular}

Fonte: elaborado pela autora a partir do acervo disponível no banco de dados da ONU e UNESCO, 2019.

Tendencialmente, os documentos que discutem o direito, a educação e o cuidado para a primeira infância no início do século XXI, apresentam a articulação entre os termos educação e cuidado para consolidar para esta etapa os compromissos de uma Educação para Todos (EPT), firmada em 1990. Ainda, observamos que há um ponto de convergência sobre a ECPI nos documentos do quadro 2: a sua suposta capacidade em reduzir as diferenças, trazendo retornos econômicos futuros às crianças e investir na infância ao entendê-la como investimento em capital humano. As intencionalidades e encaminhamentos para tanto é o que procuraremos investigar na próxima seção. 


\section{Uma agenda de ECPI: de ações intersetoriais à uma empreitada social compartilhada}

A agenda de ECPI no século XXI pode ser observada a partir dos documentos The Dakar Framework for Action (ONU, 2000), que apresenta a articulação entre os termos educação e cuidado como principal compromisso, de maneira que as crianças em maior situação de risco ou as mais vulneráveis tenham maior ênfase nas práticas assumidas; e, "Um mundo para as crianças" (ONU, 2002), pelo acordo unânime entre dirigentes mundiais em torno de uma nova agenda para as crianças do mundo, incluindo 21 metas e objetivos específicos para saúde infantil, educação e proteção, na adoção de medidas para promoção de ações nacionais e de cooperação internacional, voltada para uma boa gestão para a redução da pobreza e consolidação da colaboração com o setor privado para as políticas de ECPI. Como fazer esses encaminhamentos, seus pressupostos e suas intencionalidades, encontramos pistas e indicativos nas fontes da UNESCO selecionadas.

O documento "Bases Sólidas: Educação e Cuidados na Primeira Infância" é de autoria da Equipe do Relatório de Monitoramento Global de Educação para Todos, encomendado pela UNESCO, publicado em 2007. Adota uma abordagem holística, cuja ECPI tem como objeto o apoio à sobrevivência, ao crescimento, desenvolvimento e à aprendizagem das crianças desde o nascimento até sua entrada na escola primária em ambiente escolarizado e não escolarizado. São dirigidos aos dois grupos etários de crianças abaixo de três anos e aquelas de três até a entrada no ensino fundamental, o que já remete a uma dicotomia dentro da etapa educativa.

O investimento em programas de ECPI gera significativos retornos econômicos, eliminando a desigualdade e a inequidade, principalmente para as crianças de famílias pobres, salienta que os governos precisam assumir um papel mais proativo e desenvolver um dispositivo comumente acordado de regulação, garantia de qualidade, monitoramento e promoção da equidade, que não anulam as parcerias, pois, que para isso se efetive, os atores não-governamentais são importantes para que tais dispositivos de acesso e qualidade para a Educação Infantil se estabeleçam (UNESCO, 2007).

O relatório em tela tem como eixo central o investimento em programas de educação e cuidado como as campanhas de nutrição, imunização e conscientização das famílias, o que, ao longo de nosso estudo, os governos sustentam com ações que assegurem a sobrevivência, porém, não de todas as crianças, somente para aquelas que conseguiram ser institucionalizadas. Garantindo uma sobrevivência adequada na infância de maneira que também promova o desenvolvimento infantil, os governos podem ser capazes de estimular, a partir desse investimento, a garantia do crescimento de capital humano em suas crianças e para seus pais. 
A partir do relatório de ECPI, apreendemos que o trabalho com o cuidado do nascimento até os primeiros três anos de idade exerce influência fundamental no seu desenvolvimento futuro, que aqui é entendido como capacitação para a atuação na vida produtiva e, portanto, ressalta-se sempre a importância de educação, cuidado, higiene e nutrição. Apesar da desconsideração do desenvolvimento infantil em sua essência, mesmo com a concepção de formação integral de capital humano, a faixa etária passa despercebida nas políticas, programas e proposições dos países. Por meio de medidas equitativas e focalizadas, o que o documento aponta é para uma governança para buscar consenso entre parceiros ao fortalecimento de uma política de Educação Infantil intergerencial, pois, o formal para a educação de 4-5 e o e não formal para o 0-3, tem livre caminho para ações estreitamente de cuidado, cujo governo tem a função de regular, monitorar e promover a equidade.

No contexto latino-americano os programas de ECPI, em sua maioria, se voltam para a focalização e a vulnerabilidade, não possibilitado análise do contraste dos efeitos com diferentes grupos, uma vez que tais ações abordam a população de crianças vulneráveis, com foco na pobreza e/ou na ruralidade, que apontam efeitos positivos em alguns casos, com exceção de programas de transferência de renda cujos resultados apresentam evidências contraditórias pela falta de, no mínimo, equidade (BERLINSKI; GALIANI; MANACORDA, 2007; VARGAS-BARON, 2009; PAXSON; SCHADY, 2013).

Com vistas a entender no movimento da história às orientações de ECPI, o relatório "Declaração de Incheon: Rumo a uma educação de qualidade inclusiva e equitativa e à educação ao longo da vida para todos" (UNESCO, 2015a), encoraja "[...] o fornecimento de pelo menos um ano de educação pré-primária de qualidade, gratuita e obrigatória, bem como, que todas as crianças tenham acesso à educação, cuidado e desenvolvimento de qualidade na primeira infância" (UNESCO, 2015a, p. 4).

Para isso, o planejamento, a implementação e o monitoramento podem se beneficiar do apoio de parcerias fortes e multifacetadas, que reúnam todos os atores-chave, suas contribuições e ações potenciais. A presença da discussão de educação e cuidado é pautada no fortalecimento de parcerias multifacetadas. Para que isso se faça, a educação escolar é transferida, mais uma vez, à educação não formal para as crianças de zero a três anos, voltada às Organizações da Sociedade Civil (OSCs), cujas coalisões e redes representativas e de base ampla passam a ter papel fundamental.

As enunciações apontam para a formação de redes sociais que são compostas por um conjunto de pessoas e/ou organizações que se agregam com interesse comum, contribuem para a produção e disseminação de informações, criam canais de comunicação e estimulam a 
participação da sociedade, efetivando, portanto, uma "empreitada social compartilhada" (UNESCO, 2015a, p. 37) para ECPI. Há um esforço recente em produzir consenso em torno do projeto que defendem: parcerias com diferentes instâncias do terceiro setor para o atendimento educacional nas escolas públicas e na Educação Básica, nessa a Educação Infantil, e, para além desta, que a articulação de outros arranjos educativos para o atendimento às crianças de zero a três anos, por meio de laços formais e não-formais, conforme verificado nos outros relatórios.

A agenda estruturada deve ter o foco voltado à eficiência, à eficácia e à equidade dos sistemas educacionais, apontado como "Governança, responsabilização e parcerias” ao "[...] planejamento da educação com redução da pobreza, estratégias de desenvolvimento sustentável e respostas humanitárias, além de garantir, ao mesmo tempo, que as políticas estejam alinhadas com as obrigações legais do governo" (UNESCO, 2015a, p. 27, grifos nossos).

Enfatiza aliar ações educativas com o combate equitativo da pobreza com equidade. A questão da pobreza, nesse sentido, é enfatizada pela Early Childhool Care and Education (ECCE), reafirmando a educação e cuidados na primeira infância focalizada aos mais pobres, a ser executada pelo fortalecimento de parcerias a partir de abordagens setoriais transversais. A educação infantil é direcionada à atuação de forma transversal em sentido estrito, isto é, promover práticas de gestão intersetorial de programas integrados que abranjam necessidades de saúde, educação e nutrição para crianças e/ou responsáveis, com livre caminho para adotar parcerias na execução do atendimento da educação, principalmente a de zero a três anos.

Observamos cinco aspectos para consolidação da ECPI, em suas intencionalidades e encaminhamentos: 1) as parcerias público-privadas; 2) o acirramento da dualidade histórica da inclusão das crianças de 4-5/6 anos nos sistemas formais de ensino, ao passo que para as crianças com idades inferiores a três anos tem se enfatizado e fomentado o desenvolvimento de programas de atenção, com predomínio da chamada modalidade não formal de atendimento; 3) educação intersetorial e intergerencial; 4) focalização na pobreza para sua gestão e, assim, com a equidade, produzir capital humano; 5) educação de alguns por vias formais e preparatórias ao ensino fundamental, enquanto o cuidado de outros por vias não formais, de uma empreitada social compartilhada das parcerias entre público-privado.

Os dados apresentados nos documentos evidenciam que a prioridade dos governos locais tem sido a expansão e a universalização do atendimento das faixas etárias mais próximas da escolarização, motivo pelo qual se alertam os governantes para as precárias taxas de atendimento para as idades de 0-3 anos. A família e a comunidade são atores de ação no desenvolvimento da criança e a UNESCO se posiciona com uma atenção maior a programas de fortalecimento das famílias/comunidade no processo educacional, que, para a educação de zero 
a três anos, há uma predominância à orientação de programas que integrem saúde e educação a partir de práticas transversais e intersetoriais.

$\mathrm{O}$ fato de o atendimento educacional das crianças de zero a três anos não ser prioridade engendra a construção de alternativas que não aquelas ligadas à criação de mais vagas em creches públicas, mas buscam as possibilidades de conveniamento do poder público com instituições privadas, com a proposição das parcerias público-privada. Os arranjos indicados são muitos, mas possuem eixos centrais comuns, quais sejam: estabelecimento das parcerias público-privadas - seja no atendimento educacional ou fora dele - e a focalização nos mais pobres para destinação de recursos do Estado, o que permite a essas crianças o atendimento escolar, mas nunca possibilitarão uma verdadeira inclusão social desses sujeitos.

A Educação Infantil passa a se orientar pela convergência de duas lógicas distintas: políticas universalizadas para o grupo de 4 a 5 anos e políticas focalizadas e compensatórias para 0 a 3 anos. Campos (2012) agrupa os programas não escolarizados dirigidos à faixa etária em 4 categorias (Quadro 3).

Quadro 3 - Categorização dos programas de ECPI de zero a três anos na América Latina

\begin{tabular}{|c|c|}
\hline Local & Características \\
\hline $\begin{array}{lcr}\text { Centros } & \text { de } & \text { Educação } \\
\text { Infantil } & \text { parcial } & \text { ou } \\
\text { integral } & & \end{array}$ & $\begin{array}{l}\text { Contam com profissionais formados e voluntários; podem ser } \\
\text { abrigados em instalações públicas ou cedidas pela comunidade. Boa } \\
\text { parte dos programas situados nessa categoria são executados por } \\
\text { organizações sociais. }\end{array}$ \\
\hline $\begin{array}{l}\text { Atendimento direto, de } \\
\text { caráter socioeducativo, } \\
\text { oferecidos em espaços } \\
\text { comunitários }\end{array}$ & $\begin{array}{l}\text { Realizados por pessoas da própria comunidade, que recebem } \\
\text { orientações (treinamento) de equipes de coordenação para o } \\
\text { desenvolvimento de atividades de saúde, nutrição e educação. }\end{array}$ \\
\hline $\begin{array}{l}\text { Espaços comunitários } \\
\text { ou em centros próprios } \\
\text { destinados à atenção } \\
\text { socioeducativa }\end{array}$ & $\begin{array}{l}\text { Articulam orientação familiar, especialmente às mães, com } \\
\text { atendimento direto às crianças. O foco é o fortalecimento da relação } \\
\text { entre a família e a criança. Estes programas também podem ser } \\
\text { itinerantes (o educador comunitário vai à casa da família); }\end{array}$ \\
\hline $\begin{array}{l}\text { De caráter } \\
\text { socioeducativo dirigidos } \\
\text { às famílias }\end{array}$ & $\begin{array}{l}\text { Não implicam atendimento direto às crianças, mas seu alvo são as } \\
\text { famílias que recebem orientações sobre como estimular o } \\
\text { desenvolvimento de suas crianças. É desenvolvido por meio de visita } \\
\text { domiciliar }\end{array}$ \\
\hline
\end{tabular}

Fonte: Organizado a partir de Campos (2012, p. 26).

O consenso pretendido com as publicações é respaldado pela hegemonia dos programas e projetos desenvolvidos pelas agências da ONU, que apresenta, por um lado, uma postura universalizante ao editar documentos orientadores e, por outro, um caráter específico ao propor ações aos países em desenvolvimento, em busca da gestão da pobreza. A Educação Infantil é considerada a responsável em consolidar a qualidade de vida às crianças, a partir do 
desenvolvimento de suas estratégias de ação. Nesse sentido, se volta para a criação de capital humano:

Esses programas atestam que o desenvolvimento na primeira infância é a origem da formação do capital humano, apresenta os maiores índices de retorno no desenvolvimento econômico e também a melhor relação custobenefício para reduzir a pobreza e promover o crescimento econômico de um país. Crianças que participam de programas para o desenvolvimento da primeira infância costumam se sair melhor na escola e na vida. Os retornos dos investimentos nesses programas excedem àqueles que são associados a qualquer outro investimento na infraestrutura dos países (SCHNEIDER; RAMIRES, 2007, p. 44).

A UNESCO, como um importante OI mediador e influenciador sobre práticas, programas e políticas para a infância, indica que o investimento na Educação Infantil melhora o acesso e o desempenho das crianças na escola primária, que uma boa atenção a essas crianças garantiria nutrição, algo fundamental à aprendizagem, e que, "Dado seu impacto positivo sobre a saúde, a nutrição e os resultados da aprendizagem, os programas para a primeira infância representam um bom investimento no capital humano " (UNESCO, 2007, p. 24). As relações entre educação-erradicação da pobreza e educação para o desenvolvimento são reafirmadas em documentos como nos Objetivos do Milênio, que estabelecem metas a se cumprir até 2015, conforme Jimenez e Segundo (2007), e se efetivam em um cenário de mundo globalizado para garantir a hegemonia da reprodução capitalista, assegurada pelas organizações internacionais, seus documentos e programas.

Outro ponto a se destacar em relação ao combate à pobreza ligada ao cuidado para a educação de zero a três anos tratada na lógica da assistência é que a afasta da esfera do direito. Tratá-la como direito implica compreender que seu provimento deve se dar no âmbito do Estado, o que implica efetivos investimentos públicos em seu benefício.

A centralidade da ECPI na proposta da UNESCO constitui-se, ainda, por um duplo jogo: por um lado, a visibilidade das crianças e suas famílias e de suas misérias e, por outro, a invisibilidade das condições econômico-sociais que as produzem. Essa operação, que poderia ser compreendida apenas como um mecanismo discursivo, expressa um processo perverso de

\footnotetext{
${ }^{5}$ Vale destacar o estudo de James Heckman, da Universidade de Chicago, como uma das principais referências no que se refere à teoria do capital humano aplicada à primeira infância, orientado por um nítido viés economicista. Heckman elaborou um gráfico intitulado "Rates of Return to Human Capital Investment Initially Setting Investment to be Equal Across all Ages", sobre as taxas diferenciadas de retorno econômico dos investimentos na educação infantil, fundamental, média e superior, destacando a educação pré-escolar, amplamente destacados em documentos do Banco Mundial e da Unesco. Também em 2010, a Conferência da Unesco em Moscou, mencionada no quadro 2, demonstrou que programas destinados à primeira infância apontam que a relação custo benefício é vantajosa, em que a criança pequena é apresentada como capital humano, muito distante de uma concepção da criança como sujeito de direitos, como nos relatórios aqui analisados.
} 
repolitização da concepção de pobreza, na medida em que se introduz uma disjunção entre as condições estruturais que a produz e suas formas de manifestações, além de ressaltar a tendência dual entre o formal e não formal, que salienta a privatização e publicização dos serviços.

Após as considerações firmadas em 1989 e a presença de uma agenda comum, a focalização de programas e políticas parecem indicar mais para processos fragmentários e localizados do que para concepções mais sistêmicas e estruturadas e acordadas, regional ou globalmente, para a educação infantil.

\section{Considerações finais}

É notória uma agenda de ações para a infância aos países em desenvolvimento mediada pelos OI, na construção da AGEE em busca de CMEC. Não podemos deixar de evidenciar, amparadas em Rosemberg (2015), a existência da agenda de políticas públicas também como uma construção social e política, resultante do jogo de tensões e coalizões entre diversos atores sociais, nacionais e internacionais, de um processo que não é unilateral.

A criação de uma agenda estruturada para políticas de ECPI é fundamental quando pensamos em um primeiro momento em medidas equitativas para, posteriormente, ações que propiciassem propostas igualitárias para a Educação Infantil, na perspectiva do direito, como acordado na Convenção sobre os Direitos da Criança.

Contudo, ao observar as orientações internacionais e algumas pesquisas sobre programas para América Latina, o que encontramos é a velha tendência voltada para a gestão da pobreza, a educação escolar preparatória ao ensino fundamental para os anos finais da Educação Infantil e o cuidado por vias não formais para a educação de zero a três anos, com medidas focalizadas, intergerenciais e intersetoriais, distante da perspectiva do direito à educação de qualidade, principalmente, quando as parcerias com o privado, em vias não formais, são amplamente destacadas.

O estudo analisou as orientações e tendências da UNESCO voltadas para a ECPI aos países da América Latina e abre caminhos para investigar evidências práticas sobre os tipos de programas na região e seus impactos.

AGRADECIMENTOS: À Capes, que permitiu total dedicação para desenvolver esse estudo. 


\section{REFERÊNCIAS}

BERLINSKI, Samuel; GALIANI, Sebastian; MANACORDA, Marco. Giving children a better start: preschool attendance and school-age profiles. Gender Impact: the World Bank's Gender Impact Evaluation Database. Washington DC; World Bank, 2013.

CAMPOS, Rosania. Educação Infantil e organismos Internacionais: uma análise dos projetos em curso na América Latina e suas repercussões no contexto nacional. Tese (doutorado em Educação). Universidade Federal de Santa Catarina, Florianópolis, 2008.

CAMPOS, Rosania. A Educação Infantil e os Organismos Internacionais: Quando Focalizar não é priorizar. Archivos Analíticos de Políticas Educativas/Education Policy Analysis Archives, v. 21, p. 01-13, 2013.

CAMPOS, Roselane Fátima. "Política pequena" para as crianças pequenas? Experiências e desafios no atendimento das crianças de 0 a 3 anos na América Latina. Revista Brasileira de Educação, v. 17 n. 49 jan./abr. 2012.

CARCANHOLO, Marcelo. Neoconservadorismo com roupagem alternativa: a nova Cepal dentro do Consenso de Washington. In: CASTELO, Rodrigo (Org.). Encruzilhadas da América Latina no século XXI. Rio de Janeiro: Zahar, p. 69-79, 2010.

CEPAL. Panorama Social de América Latina, 2018. LC/PUB.2019/3-P, Santiago, 2019.

DALE, Roger. Globalização e educação: demonstrando a existência de uma 'cultura educacional mundial comum' ou localizando uma 'agenda globalmente estruturada' para a educação. Educação, Sociedade e Culturas, Porto, n. 16, p. 133- 169, 2001.

DALE, Roger. Demonstrando a existência de uma "cultura educacional mundial comum" ou localizando uma "agenda globalmente estruturada para educação". Educação e Sociedade, v.25, nº 87, Campinas/SP, mai/ago, 2004.

JIMENEZ, Susana Vasconcelos; SEGUNDO, Maria das Dores Mendes. Erradicar a pobreza e reproduzir o capital: notas críticas sobre as diretrizes para a educação do novo milênio.

Cadernos de Educação, Pelotas, n. 28, p. 119-137, jan./jun. 2007.

LÓPEZ, Néstor; D’ALESSANDRE, Vanessa. Políticas públicas para la primera infancia en América Latina. Reflexiones a 25 años de la ratificación de la Convención Internacional sobre los Derechos del Niño, 2015.

MÉNDEZ, Emilio Garcia. G. Infância, lei e democracia: uma questão de justiça. In: MÉNDEZ, Emilio Garcia; BELOFF, Mary (Org.). Infância, lei e democracia na América Latina: análise crítica do panorama legislativo no marco da Convenção Internacional dos Direitos da Criança (1990-1998). Blumenau: Edifurb, p. 21-46, 2001.

ONU. Declaração dos Direitos da Criança. Proclamada pela Resolução da Assembleia Geral das Nações Unidas n. ${ }^{\circ} 1386$ (XIV), de 20 de novembro de 1959.

ONU. Pacto Internacional sobre os Direitos Econômicos, Sociais e Culturais. Adotado e aberto à assinatura, ratificação e adesão pela resolução 2200ª (XXI) da Assembleia Geral das 
Nações Unidas, de 16 de Dezembro de 1966. Entrada em vigor na ordem internacional: 3 de Janeiro de 1976 , em conformidade com o artigo $27^{\circ}$.

PAXSON, Christina; SCHADY, Norbert. Does Money Matter? The Effects of Cash Transfers on Child Development in Rural Ecuador. World Bank Policy Research Working Paper, 4226, May 2007.

ROBEMBERG, Fúlvia. Políticas públicas e qualidade da educação infantil. In: ARTES, Amélia; UNBEHAUM, Sandra. Escritos de Fúlvia Rosemberg. Cortez: São Paulo, 2015. p. 216-237.

ROSEMBERG, Fúlvia. Organizações multilaterais, estado e políticas de educação infantil. Cadernos de Pesquisa, n. 115. São Paulo, mar. 2002.

ROSEMBERG, Fúlvia; MARIANO, Carmem Lúcia Sussel. A convenção internacional sobre os direitos da criança: debates e tensões. Cadernos de Pesquisa, v. 40, n. 141, p.693-728, set./dez. 2010.

SCHNEIDER, Alessandra; RAMIRES, Vera Regina. Primeira infância melhor: uma inovação em política pública. Brasília: UNESCO, Secretaria de Saúde do Estado do Rio Grande do Sul, 2007.

SHIROMA, Eneida Oto; CAMPOS, Roselaine Fátima; GARCIA, Rosalba Maria Cardoso. Decifrar textos para compreender a política: subsídios teórico-metodológicos para análise de documentos. Perspectiva, v. 23, n. 2, p. 427-446. jul./dez. 2005.

UNESCO. The Dakar Framework for Action. Paris: Graphoprint, 2000.

UNESCO; OCDE. Educação e Cuidado na Primeira Infância: grandes desafios. Brasília: UNESCO; OCDE; Ministério da Saúde, 2002.

UNESCO/OREALC. Participación de las familias en la Educación Infantil Latinoamericana. Santiago, Chile, agosto, 2004a.

UNESCO. Síntesis regional de indicadores de la primera infancia. Santiago, Chile, mayo, 2004b.

UNESCO. Bases Sólidas: educação e cuidados na primeira infância - relatório conciso. Brasília: UNESCO, 2007.

UNESCO. Conferência Mundial sobre Educação e Cuidado na Primeira Infância: Marco de Ação e de Cooperação de Moscou - aproveitar a riqueza das Nações. Brasília: UNESCO, 2010.

UNESCO. 2014-2021 Medium-Term Strategy. Paris: UNESCO, 2014.

UNESCO. BRICS Construir a educação para o futuro: Prioridades para o desenvolvimento nacional e a cooperação internacional. Brasília: UNESCO, 2014.

UNESCO. Ensinar e Aprender: alcançar a qualidade para todos - Relatório Conciso. Brasília: UNESCO, 2014. 
UNESCO. Declaração de Incheon Educação 2030: rumo a uma educação de qualidade inclusiva e equitativa e à educação ao longo da vida para todos. Brasília: UNESCO, 2015a.

UNESCO. Educação para todos 2000-2015: progressos e desafios - Relatório Conciso. Brasília: UNESCO, 2015 b.

UNICEF. Declaração Universal dos Direitos das Crianças. 1989. Disponível em: http://bvsms.saude.gov.br/bvs/publicacoes/declaracao_universal_direitos_crianca.pdf Acesso em: 01 ago. 2018.

VARGAS-BARÓN, Emily. Going to Scale: Early Childhood Development in Latin America. World Bank, The RISE Institute, Washington, DC, March. 2009.

\section{Como referenciar este artigo}

BORTOT, C. M.; LARA, A. M. B. As políticas de Educação e Cuidados na Primeira Infância para a América Latina: intencionalidades e encaminhamentos na proposta da UNESCO. Revista Ibero-Americana de Estudos em Educação, Araraquara, v. 14, n. esp. 3, p. 17671781, out., 2019. E-ISSN: 1982-5587. DOI: 10.21723/riaee.v14iesp.3.12762

Submetido em: 25/03/2019

Revisões requeridas: 20/04/2019

Aceito em: 15/05/2019

Publicado em: 30/08/2019 